Histology, Cytology and Embryology (HCE)

\title{
Retinochoroidal anastomoses in RCS rat eyes?
}

\author{
Christian Albrecht May* \\ Department of Anatomy, Medizinische Fakultät Carl Gustav Carus, TU Dresden, 01307 Dresden, Germany
}

\begin{abstract}
The Royal College of Surgeons (RCS) dystrophic rat is an established model for retinal degeneration due to retinal pigment epithelium dysfunction. In the present study anastomoses from retinal neovascularizations towards venules of the choroid could be demonstrated by scanning electron- and light microscopy. They develop some time after retinal degeneration showing most contacts at 6 months of age. As a self-limiting process, the number decreased in older animals.
\end{abstract}

\section{Introduction}

The pathogenesis of chorioretinal anastomoses is described as a choroidal neovascularization towards the retina followed by the development of an anastomosing retinal vessel [1]. This happens in most sub-types of age-related macular degeneration [2-6]. Some single reports describe this pathology after toxoplasmosis and histoplasmosis infection [7,8], trauma [9], and radiatory and photodynamic therapy $[10,11]$. The effect is also used for the therapy of chronic central vein occlusion [12].

Retinochoroidal anastomoses, in contrast, are thought to primarily start with proliferation of retinal vessels. This is hypothesized for a different sub-type of macular degeneration named retinal angiomatous proliferation. A number of animal models exist where retinal vessels start to proliferate and form subretinal neovascular ravels. Only rarely a connection to the choroid vasculature is mentioned, e.g. in the VLDLR knockout mouse $[13,14]$. It is unknown, how these contacts can occur.

In Royal College of Surgeon (RCS) rats with inherited retinal degeneration proliferation of retinal vessels into the retinal pigmented epithelium (RPE) is a well-known phenomenon. After contact with the RPE the retinal capillaries become fenestrated $[15,16]$, show increased permeability for horseradish peroxydase $[17,18]$ and increase in carbonic anhydrase activity [19]. In the process of retinal degeneration, the morphology of the retinal capillary network changes considerably. The number of capillaries in the usually vascularised layers of the retina decreases showing narrowed diameters of the capillaries [20]. On the other hand, capillaries in contact with the RPE sprout so that the total capillary length increases $[21,22]$. According to El Hifnawi sprouting is not refined to the retina but takes also place towards the choroid forming anastomoses between retinal and choroidal vessels [23]. Other authors, however, denied the development of real shunts between the two vascular systems in RCS rats [24-26]. In the current study the retinal vasculature of RCS rats was investigated using scanning electron microscopy of corrosion cast preparations, light microscopy and transmission electron microscopy to study the following questions:

a) do retinochoroidal anastomoses occur in dystrophic RCS rats?

b) Is there a specific localization of these anastomoses?

c) Does the tissue around these anastomoses show any specific characteristics?

\section{Material and methods}

All animals used in this study were treated in accordance with the ARVO statement for the Use of Animals in Ophthalmic and Vision Research.

\section{Scanning electron microscopy}

For scanning electron microscopy eleven adult pink-eyed retinal dystrophic RCS rats $(3,3,3,6,6,6,12,12,21,23,28$ months of age) and seven age matched pink-eyed RCS-rdy+congenic controls (3, $7,7,12,24,24,26$ months of age) were used. After deep thiopental anesthesia, the animals were transcardially perfused with Expafusin (Ringer), containing heparin to prevent clotting. The descending Aorta was then clamped and the vessels transcardially perfused with liquid plastic, containing Araldite CY 223 (50\%), hardener HY 2267 (30\%) and acetone (20\%). After hardening for $12 \mathrm{~h}$ in situ the eyes were enucleated, incised nasally and macerated in concentrated $\mathrm{KOH}$ for about three weeks, the solution being changed daily. Any concrements were removed with $5 \% \mathrm{HCl}$, the specimen then rinsed out with distilled water and dried. Fixed on a holder they were sputtered with gold and studied with a scanning electron microscope (Stereoscan 90, Cambridge).

\section{Light and transmission electron microscopy}

For light and transmission electron microscopy 7 pink-eyed retinal dystrophic RCS rats $(3,6,6,6,10,12,24$ months of age) and 5 age matched pink-eyed RCS-rdy+congenic controls $(3,6,7,13,22$ months of age) were used. Under deep thiopental anesthesia the animals were transcardially perfused with heparinised Expafusin and then with $4 \%$ neutral buffered formalin. After enucleation the eyes were brought in Ito's solution ( $2.5 \%$ glutaraldehyde, $2.5 \%$ paraformaldehyde, $0.1 \%$ picric acid in cacodylate buffer, $\mathrm{pH}$ 7.4) and fixed for at least 12 hours. Tissue samples were post-fixed in $1 \%$ osmium tetroxide, dehydrated in alcohol and embedded in Epon. $1 \mu \mathrm{m}$-thick serial sections were stained

Correspondence to: Christian Albrecht May, Anatomisches Institut, Medizinische Fakultät Carl Gustav Carus, Fetscherstr. 7401307 Dresden, Germany, Tel: +49351-4586105; Fax: +49-351-4586303; E-mail: Alrecht.May@mailbox.tu-dresden.de

Key words: retina, choroid, anastomosis, RCS rat, vasculature

Received: April 11, 2017; Accepted: May 08, 2017; Published: May 11, 2017 
with toluidin blue. Ultra-thin sections were post stained with uranyl acetate and lead citrate, and then examined on a Zeiss EM 109 electron microscope.

\section{Results}

\section{Scanning electron microscopy}

RCS-rdy+ congenic controls revealed a dense and regular network of retinal vessels at all age points investigated. Neither neovascularization nor retinochoroidal anastomoses could be detected. The choriocapillaris formed a defined layer of confluent capillary lobules showing thicker diameters than the retinal capillaries.

In dystrophic RCS rats the total number of retinal vessels as well as the figuration of the capillaries showed age-related changes: in animals 3 months of age the capillaries formed a dense and regular network (Figure 1A). At 6 months of age there was still a dense layer of retinal vessels, showing however more vessels located directly on the choriocapillary layer and forming loops (Figure 1B) or even larger conglomerates (Figure 1C). In eyes of rats 12 months of age and older vessel free areas were next to areas with large conglomerates of capillaries (Figure 1D). At no time point, proliferative changes could be detected in the choriocapillary layer. Its reaction to loss of RPE was purely dystrophic as described already previously [30].

At places, retinal vessels (continuous with the remaining retinal capillary bed) with diameters around 7-9 $\mu \mathrm{m}$ showed clear penetration through the choriocapillary layer into the choroid (Figure 2). These contacts could be found in all of the dystrophic eyes. In 3 months old animals there were only 2-3 of these contacts in the whole retina. Most of these penetrations were found in the eyes of 6 months old animals. Next to true identifiable penetrations there were always some indifferent contacts and loops, which seem to penetrate the choriocapillary layer without forming choroidal anastomoses. The total number of true anastomoses differed between 19 and 40 in each eye, showing a slight pronunciation in the upper quadrants (Table 1). In the old animals (12 months of age and older) the number of penetrating vessels was highly reduced to 3-6 in different quadrants of each eye.
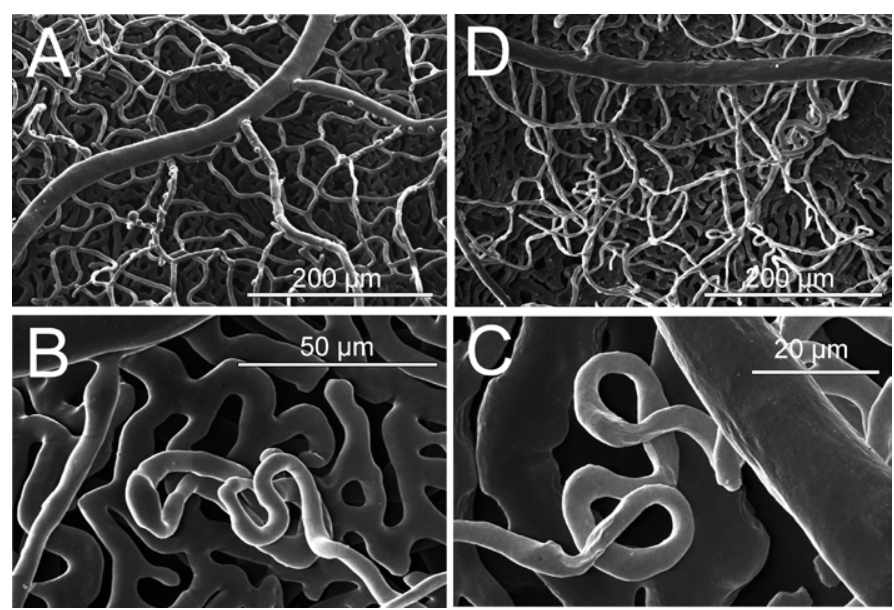

Figure 1. A-D. Scanning electron micrographs of retinal vessels in dystrophic RCS rats. A) At 3 months of age, a homogenous capillary bed is present.

$\mathrm{B}$ and C) At 6 months of age, neovascularisations occur located at the level of the retinal pigmented epithelium, either in form of loops (C) or larger conglomerates (D).

D) At 12 months of age, the appearance of the retinal vasculature is inhomogenous, showing vessel free areas next to larger conglomerates.

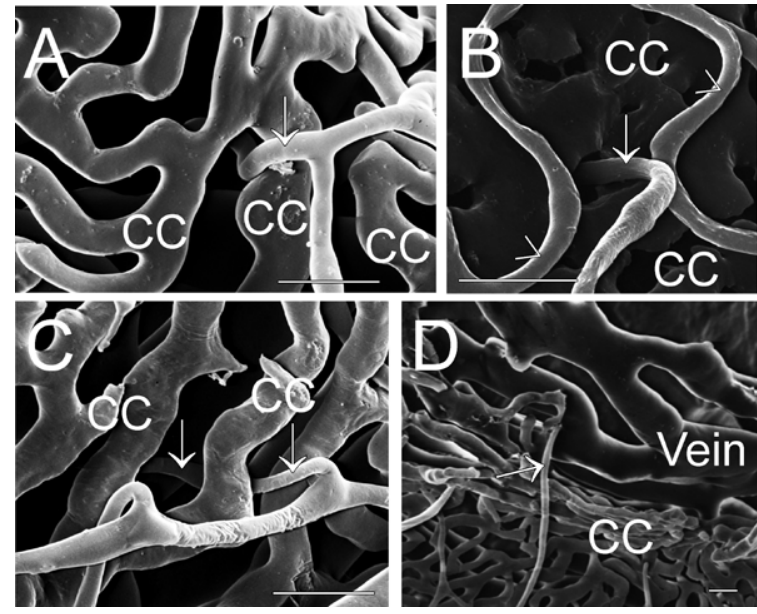

Figure 2. A-D. Scanning electron micrographs of penetrating retinal vessels (marked by arrows) through the choriocapillary layer (cc) in 6 months old dystrophic RCS rats. Scale bar $=20 \mu \mathrm{m}$.

$\mathrm{A}$ and $\mathrm{B}$ ) view from the retina at two different locations.

$\mathrm{C}$ and $\mathrm{D}$ ) show the same penetrating vessel: normal view from the retina shows the continuity of the vessel below the choriocapillaries. After partial removal of the choriocapillaris and rotation of the specimen the connection to a choroidal venule (vein) can be demonstrated.

Table 1. Distribution of retinal vessels penetrating the choriocapillary layer in the right eye of dystrophic RCS rats: true penetrations/questionable penetrations/loops. They are mos frequent in the 6 months old animals (bold lines).

\begin{tabular}{|l|c|c|c|c|}
\hline $\begin{array}{c}\text { Age } \\
\text { (months) }\end{array}$ & $\begin{array}{c}\text { Upper nasal } \\
\text { quadrant }\end{array}$ & $\begin{array}{c}\text { Upper } \\
\text { temporal } \\
\text { quadrant }\end{array}$ & $\begin{array}{c}\text { Lower } \\
\text { temporal } \\
\text { quadrant }\end{array}$ & $\begin{array}{c}\text { Lower nasal } \\
\text { quadrant }\end{array}$ \\
\hline 3 & $1 / 1 / 0$ & $0 / 0 / 0$ & $0 / 1 / 0$ & $1 / 0 / 0$ \\
\hline 3 & $0 / 1 / 0$ & $1 / 1 / 0$ & $2 / 0 / 0$ & $0 / 0 / 0$ \\
\hline $\mathbf{6}$ & $\mathbf{9} 4 / \mathbf{2}$ & $\mathbf{3 / 5 / 0}$ & $\mathbf{5 / 4 / 0}$ & $\mathbf{2 / 2} \mathbf{0}$ \\
\hline $\mathbf{6}$ & $\mathbf{1 6 / 1 0 / 2}$ & $\mathbf{1 6 / 7 / 3}$ & $\mathbf{3 / 4 / 1}$ & $\mathbf{5 / 6 / 2}$ \\
\hline $\mathbf{6}$ & $\mathbf{1 1 / 8 / 1}$ & $\mathbf{9 / 6 / 0}$ & $\mathbf{6 / 2 / 2}$ & $\mathbf{4 / 5 / 0}$ \\
\hline 12 & $2 / 1 / 0$ & $3 / 2 / 0$ & $0 / 1 / 0$ & $1 / 0 / 0$ \\
\hline 12 & $0 / 0 / 0$ & $2 / 0 / 1$ & $1 / 0 / 0$ & $0 / 1 / 0$ \\
\hline 23 & $1 / 1 / 0$ & $1 / 0 / 0$ & $2 / 1 / 0$ & $0 / 2 / 0$ \\
\hline
\end{tabular}

\section{Light and transmission electron microscopy}

Serial semi thin sections of dystrophic RCS rat posterior eye segments revealed that all retinal neovascularizations were in close contact to the RPE with no exception (Figure 3). Areas with complete loss of RPE revealed retinal vasculature atrophy and no vessels were even close to Bruch's membrane. The underlying choriocapillaris in these regions was degenerated, too.

If conglomerates of capillaries were studied within the RPE layer, the endothelium always showed fenestrations. Sections of single vessels, in contrast, also showed preserved non-fenestrated endothelium (Figure 4A). At places, remnants of former retinal vessels named 'ghost vessels' were seen within the RPE (Figure 4B).

Series of several hundred consecutive semi thin sections of 6 months old dystrophic RCS rat eyes failed to demonstrate a clear penetrating vessel from the retina towards the choroidal stroma. At rare places Bruch's membrane showed a clear interruption different of those artificial ones near the cutting edges. The interruption occurred in regions with retina neovascularization (Figure 5) the stroma of the underlying choroid was loosened. At other places within the choroid, 


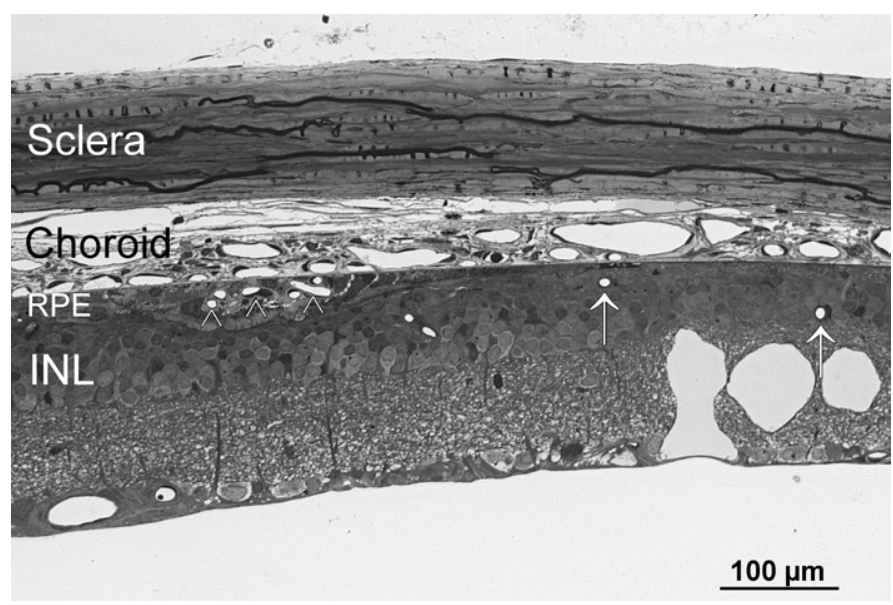

Figure 3. Light microscopic overview of the retina and choroid of a 6 months old dystrophic RCS rat. Note the conglomerate of newly formed vessels in the RPE layer (arrowhead). In RPE-free regions (right side of the micrograph), retinal vessels (arrows) are all in some distance to the choroid and the constant choriocapillaries as seen on the left side are no longer present. $\mathrm{INL}=$ inner nuclear layer of the retina.
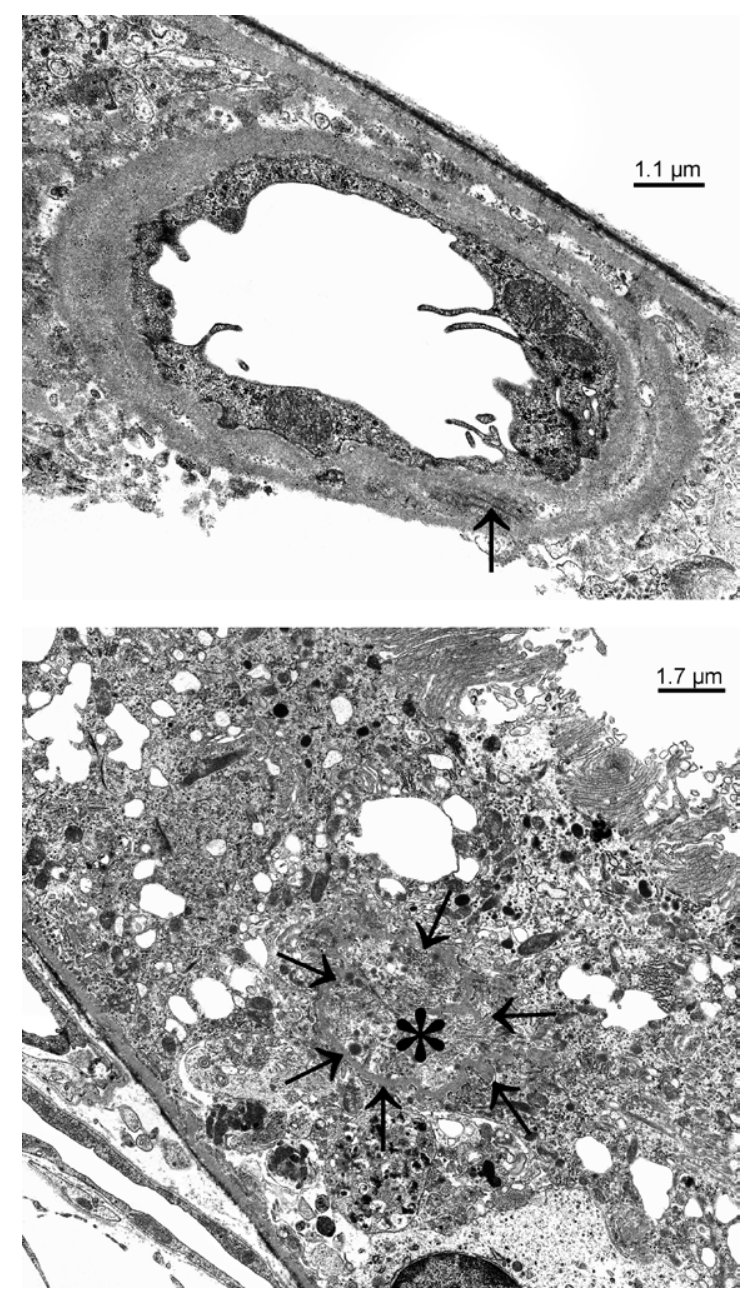

Figure 4. A,B. Transmission electron micrographs of a 6 months old dystrophic RCS rat showing newly formed vessels within the RPE layer.) single vessels show a non-fenestrated endothelium with microvilli-like processes and long spacin collagen (arrow). b) 'ghost vessels' within the RPE show a continuous basal membrane (arrows), filled with collagen (asterisks), but no endothelium and no lumen.

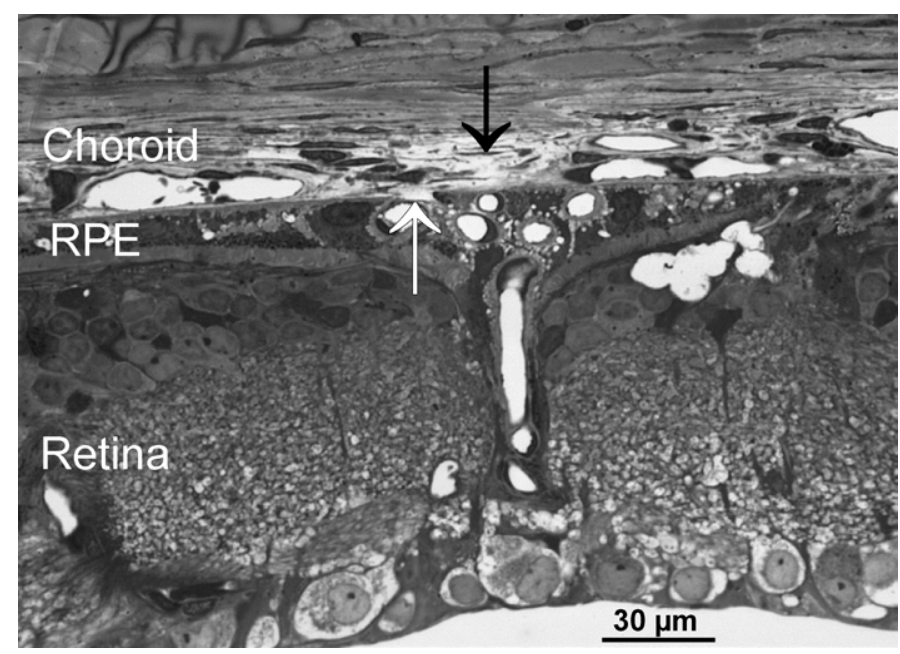

Figure 5. Light microscopic image showing an area of disrupted Bruch's membrane (white arrow). The RPE layer is present and filled with some newly formed vessels. The underlying stroma of the choroid (black arrow) is loosened.

vessels revealed a retinal-vasculature-like appearance with thickened basal membrane, otherwise not present in choroidal vessels.

\section{Discussion}

In contrast to El Hifnawi, who suggested anastomoses between the retina and the choriocapillaris, we could demonstrate clear connections between newly formed retinal vessels located in the RPE layer and larger choroidal venules in corrosion cast preparations [23]. The retinal vessels penetrated the choriocapillary layer without forming contact to the choriocapillaris itself. A similar description exists for a laser-treated rat model [27] with the difference that in dystrophic RCS rats theses contacts developed naturally without iatrogenic manipulation. In the most recent functional study on RCS rat retinal vessels using high resolution fluorescein imaging, only the leakages due to endothelial fenestration were described [28]. Anastomoses were probably not taken into account.

Although Figure 3 might share simmilarities to sections of choroidal neovascularizations, scanning electron micrographs of corrosion casts clearly show that the vascular conglomerates within the RPE cells (so called 'RPE-neovascularizations') are continuous with the retinal vascular bed and never show a capillary sprouting from the choriocapillaris. Therefore, neovascularization from the choroid can definitely be ruled out in this animal model. Moreover, at numerous places vascular conglomerates from the retinal capillary bed were seen without contacting vessels to the choroid. The underlying choriocapillaris was both completely normal in scanning microscopy of corrosion casts and in light and transmission electron microscopy.

Interestingly, the highest number of these contacts was found in 6 months old animals, while after one year of age the number of anastomoses was clearly reduced. Therefore, the formation of these contacts is time-sensitive and self limited. So far there is no hint from the literature to why this peak in adult rats might occur. Unfortunately, angiogenic factors like VEGF, Ang-2 and SRIF were studied only in young RCS rats up to 6 weeks of age [29]. While remnants of former vessels exist in the retina and RPE as 'ghost vessels' $[16,23,25,26]$, no such vessels were found in the choroid or next to Bruch's membrane. Thus, a different remodeling of the tissue seems to take place in collagenous tissue with complete removal of vascular remnants. This holds also true for the atrophy of the choriocapillaris in old RCS rats [30]. 
To further understand the pathophysiological event of the formation of true retinochoroidal anastomoses, a closer look at the morphology revealed some important aspects.

For one it is necessary, that RPE cells and the choriocapillaris are still present. Neovascularization was never present in areas of complete RPE absence. On the other hand, anastomoses derived exclusively from neovascular vessels located directly above the choriocapillaris. Therefore, the idea of metabolic or oxygen needs from the vasculature as a trigger event can be ruled out. Hypoxia might only count for inner retinal neovascularization $[31,32]$.

Which cells guide Bruch's membrane disruption? Apparent inflammatory cells were not present at the time points studied. Factors from the choroid can do [33], but in this specific situation the interaction is by far unclear. Again, the RPE might play some role but there is no further evidence in the literature. Interestingly, the underlying choroid showed clear changes in the region of Bruch's membrane disruption. The disruption, a rare and temporary event, seems to be necessary for retinal vessels to sprout into the choroid. There, the vessels are no longer surrounded by RPE cells but contact nearby venules. This is another unexplained striking event: there is no data on RPE cells growing into the choroid even after Bruch's membrane disruption other than carcinoma cells [34]. Which factors guide the capillaries away from the RPE cells towards the choroidal venules?

Further research can address the above raised questions and might be able to more precisely describe the underlying pathomechanisms.

\section{References}

1. Scott AW, Bressler SB (2010) Retinal angiomatous proliferation or retinal anastomosis to the lesion. Eye (Lond) 24: 491-496. [Crossref]

2. Costa RA, Calucci D, Paccola L, Jorge R, Cardillo JA, et al. (2005) Occult chorioretinal anastomosis in age-related macular degeneration: a prospective study by optical coherence tomography. Am J Ophthalmol 140: 107-116. [Crossref]

3. Gass JD, Agarwal A, Lavina AM, Tawansky KA (2003) Focal inner retinal hemorrhages in patients with drusen: an early sign of occult choroidal neovascularization and chorioretinal anastomosis. Retina 23: 741-751. [Crossref]

4. Obata R, Yanagi Y, Kami J, Takahashi H, Inoue Y, et al. (2006) Polypoidal choroidal vasculopathy and retinochoroidal anastomosis in Japanese patients eligible for photodynamic therapy for exudative age-related macular degeneration. Jpn $J$ Ophthalmology 50: 354-360.

5. Freund KB, Ho IV, Barbazetto IA, Koizumi H, Laud K, et al. (2008) Type 3 neovascularization: the expanded spectrum of retinal angiomatous proliferation. Retina 28: 201-211. [Crossref]

6. Slakter JS, Yannuzzi LA, Schneider U, Sorenson JA, Ciardella A, et al. (2000) Retinal choroidal anastomoses and occult choroidal neovascularization in age-related macular degeneration. Ophthalmology 107: 742-753. [Crossref]

7. Saari M, Miettinen R, Nieminen H, Räisänen S (1975) Retinochoroidal vascular anastomosis in toxoplasmic chorioretinitis. Report of a case. Acta Ophthalmol (Copenh) 53: 44-51. [Crossref]

8. Slusher MM, Tyler ME (1980) Choroidoretinal vascular anastomoses. Am J Ophthalmol 90: 217-222. [Crossref]

9. Goldberg MF (1978) Chorioretinal vascular anastomoses after perforating trauma to the eye. Am J Ophthalmol 85: 171-173. [Crossref]

10. Mendrinos E, Pilly B, Baglivo E, Donati G, Safran AB, et al. (2009) Chorioretinal anastomosis as a rare complication of radiation retinopathy. Acta Ophthalmol 87: 473475. [Crossref]

11. Yodoi Y, Tsujikawa A, Otani A, Aikawa H, Yoshimura N (2008) Chorioretinal anastomosis after photodynamic therapy for polypoidal choroidal vasculopathy: CRA after PDT for PCV. Int Ophthalmol 28: 297-299. [Crossref]

12. McAllister IL, Gillies ME, Smithies LA, Rochtchina E, Harper CA, et al. (2010) The Central Retinal Vein Bypass Study: a trial of laser-induced chorioretinal venous anastomosis for central retinal vein occlusion. Ophthalmology 117: 954-965. [Crossref]
13. Heckenlively JR, Hawes NL, Friedlander M, Nusinowitz S, Hurd R, et al. (2003) Mouse model of subretinal neovascularization with choroidal anastomosis. Retina 23 518-522. [Crossref]

14. Hu W, Jiang A, Liang J, Meng H, Chang B, et al. (2008) Expression of VLDLR in the retina and evolution of subretinal neovascularization in the knockout mouse model's retinal angiomatous proliferation. Invest Ophthalmol Vis Sci 49: 407-415. [Crossref]

15. Matthes MT, Bok D (1985) Blood vascular abnormalities in animals with inherited retinal degeneration. In La Vail MM, Hollyfield JG, Anderson RE (eds). Retinal Degeneration: Experimental and Clinical Studies. New York: Alan R Liss, USA: 209237.

16. Burns MS, Hartz MJ (1992) The retinal pigment epithelium induces fenestration of endothelial cells in vivo. Curr Eye Res 11: 863-873. [Crossref]

17. Essner E, Pino RM, Griewski RA (1979) Permeability of retinal capillaries in rats with inherited retinal degeneration. Invest Ophthalmol Vis Sci 18: 859-863. [Crossref]

18. Caldwell RB (1987) Blood-retinal barrier changes in the retinal pigment epithelium of RCS rats with inherited retinal degeneration. In Hollyfield JG, Anderson RE, LaVali MM (eds) Degenerative Retinal Disorders: Clinical and Laboratory Investigations. New York: Alan R Liss, USA: 333-347.

19. Eichhorn M, Schreckenberger M, Tamm ER, Lütjen-Drecoll E (1996) Carbonic anhydrase activity is increased in retinal pigmented epithelium and choriocapillaris of RCS rats. Graefes Arch Clin Exp Ophthalmol 234: 258-263. [Crossref]

20. Gerstein DD, Dantzker DR (1969) Retinal vascular changes in hereditary visual cell degeneration. Arch Ophthalmol 81: 99-105. [Crossref]

21. LaVail MM (1979) The retinal pigment epithelium in mice and rats with inherited retinal degeneration. In Zinn KM, Marmor MF (eds). The Retinal Pigment Epithelium. Cambridge: Harvard University Press 357-380.

22. Caldwell RB, Roque RS, Solomon SW (1989) Increased vascular density and vitreoretinal membranes accompany vascularization of the pigment epithelium in the dystrophic rat retina. Curr Eye Res 8: 923-937. [Crossref]

23. El-Hifnawi E (1985) Pathomorphologische Untersuchungen zum Verlauf der hereditären Netzhaut-Dystrophie bei RCS-Ratten. Stuttgart: Enke Verlag, Germany.

24. Bellhorn RW, Burns MS, Benjamin JV (1980) Retinal vessel abnormalities of phototoxic retinopathy in rats. Invest Ophthalmol Vis Sci 19: 584-595. [Crossref]

25. van Driel D, Provis JM, Billson FA (1988) Morphology of intraretinal new vessels in the PETH rat. Graefes Arch Clin Exp Ophthalmol 226: 576-582. [Crossref]

26. Caldwell RB (1989) Extracellular matrix alterations precede vascularization of the retinal pigment epithelium in dystrophic rats. Curr Eye Res 8: 907-921. [Crossref]

27. Vijayasekaran S, Yu DY, McAllister IL, Barry C, Constable IJ (1994) Significance of Bruch's membrane in the creation of iatrogenic chorioretinal venous anastomosis. Curr Eye Res 13: 29-33. [Crossref]

28. Zambarakji HJ, Keegan DJ, Holmes TM, Halfyard AS, Villegas-Perez MP, et al. (2006) High resolution imaging of fluorescein patterns in RCS rat retinae and their direct correlation with histology. Exp Eye Res 82: 164-171. [Crossref]

29. Prokosch V, Fink J, Heiduschka P, Melkonyan H, Thanos S (2011) VEGF, Ang-2 and SRIF associated abnormal postnatal development of the retinal capillary network in the Royal College of Surgeons rat. Exp Eye Res 92: 128-137. [Crossref]

30. May CA, Horneber M, Lütjen-Drecoll E (1996) Quantitative and morphological changes of the choroid vasculature in RCS rats and their congenic controls. Exp Eye Res 63: 75-84. [Crossref]

31. Sapieha P, Joyal JS, Rivera JC, Kermorvant-Duchemin E, Sennlaub F, et al. (2010) Retinopathy of prematurity: understanding ischemic retinal vasculopathies at an extreme of life. J Clin Invest 120: 3022-3032. [Crossref]

32. Rey S, Semenza GL (2010) Hypoxia-inducible factor-1-dependent mechanisms of vascularization and vascular remodelling. Cardiovasc Res 86: 236-242. [Crossref]

33. Heriot WJ, Henkind P, Bellhorn RW (1984) Choroidal neovascularization can digest Bruch's membrane: A prior break is not essential. Ophthalmology 91:1603-1608.

34. Minckler D, Allen AW Jr (1978) Adenocarcinoma of the retinal pigment epithelium. Arch Ophthalmol 96: 2252-2254. [Crossref]

Copyright: (C2017 May CA. This is an open-access article distributed under the terms of the Creative Commons Attribution License, which permits unrestricted use, distribution, and reproduction in any medium, provided the original author and source are credited. 